\title{
Grillage modeling approach applied to simple-span slab- girder skewed bridges for dynamic analysis
}

\author{
Miriam Guadalupe López Chávez ${ }^{1}$, António Arêde², José Manuel Jara \\ Guerrero ${ }^{3}$, Pedro Delgado ${ }^{4}$, Humberto Varum ${ }^{5}$ \\ 1,2,5 Department of Civil Engineering, Faculty of Engineering, University of Porto, Porto, \\ Portugal; ${ }^{3}$ Faculty of Civil Engineering, University of Michoacan, Michoacan, Mexico; \\ ${ }^{4}$ Polytechnic Institute of Viana do Castelo, Viana do Castelo, Portugal \\ (1miriam.Ich86@gmail.com,2aarede@fe.up.pt,3jmjara@zeus.umich.mx, \\ ${ }^{4}$ pdelgado@estg.ipvc.pt, ${ }^{5}$ hvarum@fe.up.pt)
}

\begin{abstract}
This study involves the applicability of a simplified modeling technique to simplespan slab-girder skewed bridges for dynamic analysis, based on grillage modeling strategies. To evaluate the applicability of this technique, skew angles ranging from $0^{\circ}$ to $60^{\circ}$ are studied. The ability to capture vibration modes of grillage models is compared with three-dimensional (3-D) finite element (FE) models, using shell and frame elements. The effect of the skew angle in the grillage modeling technique of the bridge's deck and the grillage model accuracy associated with the orientation of the transverse grillage members (TGMs) are studied. The grillage modeling technique eliminates shell elements to model the slab, reducing the number of degrees of freedom and the computational time in the bridge model, but, although its simplicity, demonstrates good ability to capture the vibration modes.
\end{abstract}

Subject Headings. Bridge, Civil Engineering

Author Keywords. Skewed Bridges, Modeling Technique, Grillage Analogy, Modal Analysis

\section{Introduction}

In order to maintain the geometry and the straight alignment in a road design, bridges with skew-angled supports (a.k.a. 'skewed bridges') have been used frequently for planning and design of highways, and their number has increased all over the world in the last years. However, skewed bridges are more vulnerable to severe earthquake-induced damage than straight bridges with regular geometry (Jennings et al. 1971). Skewed bridges are characterized by their skew angle, defined as the angle between the centerline of a support (abutment or pier) and a line normal to the bridge centerline (AASHTO 2012), as illustrated in Figure 1.

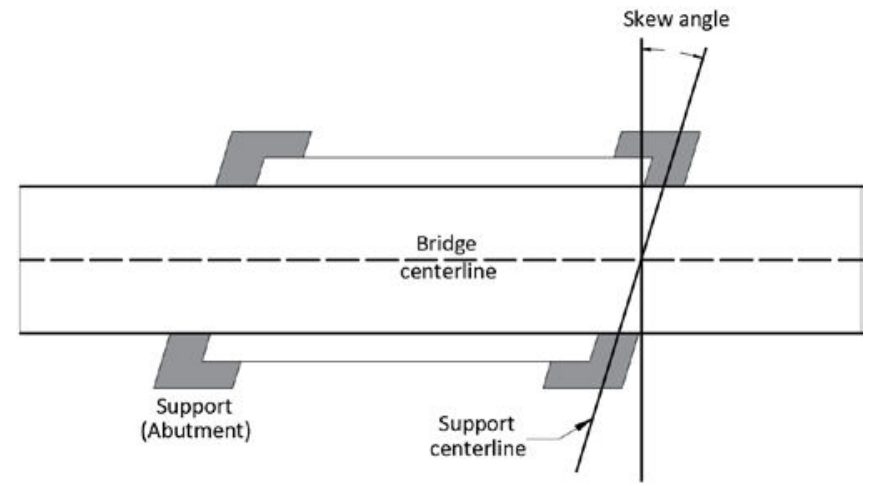

Figure 1: Plan of view of a skew bridge 
Scientific research after major earthquakes has contributed to improve the understanding of seismic performance of bridges, and to modify existing design guidelines and analysis procedures. Simultaneously, a large number of studies on the modeling and seismic response of skewed bridges have been carried out (e.g. Abdel-Mohti and Pekcan 2013, Bjornsoon, Stanton, and Eberhard 1998, Ghobarah and Tso 1974, Kaviani, Zareian, and Taciroglu 2014, Maleki 2001, Maragakis and Jennings 1987, Meng, Lui, and Liu 2001, Saiidi and Orie 1992, Wakefield, Nazmy, and Billington 1991). Notwithstanding this progress, the inherent and complex behavior of skewed bridges subjected to seismic loads is not completely clarified. As a result, the seismic vulnerability of this type of bridges remains uncertain.

The assumptions in the analytical modelling of skewed bridges have a direct effect on the results. The underlying assumptions relate to material modeling, response characteristics of the components, boundary conditions, soil-structure interaction, component modeling [i.e. beam-stick (BS) \& finite element (FE)], superstructure, seismic mass, etc. (Abdel-Mohti and Pekcan 2013, Haque and Bhuiyan 2012). This paper discusses typical modeling techniques used for skewed bridges, which is the first step in the development of a bridge model.

Over the years, different modeling techniques have been developed by researchers to analyze bridges under seismic loads. A bridge superstructure can be modeled in a variety of ways, most of them focused in the superstructure idealization, ranging from the very simple BS model to the rather sophisticated FE model. However, some modeling techniques of bridges available in the literature introduce geometric and compatibility errors, which can affect their ability to capture the actual seismic behavior of the structure. Furthermore, an irregular geometry, as in the case of skewed bridges, can increase the model errors.

A suitable modeling technique should be capable of capturing the vibration modes of the bridge subjected to seismic excitation (Meng and Lui 2002). Since the free vibration of skewed bridges is greatly affected by the skew angle, the modeling technique selected must take into consideration the effect of this parameter. Higher modes such as twisting and coupled flexural-torsional are important in assessing the seismic response of skewed bridges. Neglecting higher modes can introduce significant errors in the results of dynamic analysis (Aviram, Mackie, and Stojadinovic 2008).

Since BS models are incapable to properly capture twisting and coupled flexural-torsional vibrations, some researches propose the use of refined models for dynamic analysis of skewed bridges. The improved BS models proposed by Meng and Lui (2002) and Abdel-Mohti and Pekcan (2013), conduct to conclude that the increase of the number of lines of frame elements in BS models, produces more accurate results.

Alternatively to BS models, accurate results can be expected when idealizing a bridge superstructure as a grillage (Memory, Thambiratnam, and Brameld 1995). In the grillage modeling approach applied to slab-girder bridges, an equivalent grillage represents the three primary components of this type of bridges, namely: (1) the longitudinal girders, (2) the transverse end and intermediate diaphragms, and (3) the slab. Frame elements model the superstructure in both directions, eliminating the shell elements representing the slab.

This study analyzes the applicability of a simplified technique to model slab-girder skewed bridges, based on grillage modeling strategies. The ability of models, constructed with a grillage modeling approach (hereinafter referred to as 'grillage models') to accurately capture vibration modes is compared with three-dimensional (3-D) FE models, using shell and frame elements. Due to the inherent behavior of skewed bridges, this paper discusses the influence of skew angle in the grillage modeling technique of the bridge's deck. 


\section{Description of the Study}

To evaluate the applicability of grillage modeling approach to simple-span slab-girder skewed bridges, the response of bridge models with skew angle ranging from $0^{\circ}$ to $60^{\circ}$ is studied. The bridges have a span length of $L=20 \mathrm{~m}$, with a superstructure width of $W=10.60 \mathrm{~m}$. The superstructure is composed by six Type-IV AASTHO prestressed concrete (PC) girders (equally spaced at $1.80 \mathrm{~m}$ on-center), behaving compositely with a $0.20 \mathrm{~m}$ thick reinforced concrete (RC) slab. Figure 2 shows the transverse cross-section of the superstructure. The bridges have RC end diaphragms and an intermediate diaphragm, aligned along the skew angle. These transverse members provide stability of longitudinal girders and distribute vertical and lateral loads, while providing restraint for lateral-torsional buckling of the girders (Maleki and Hojat Jalali 2012).

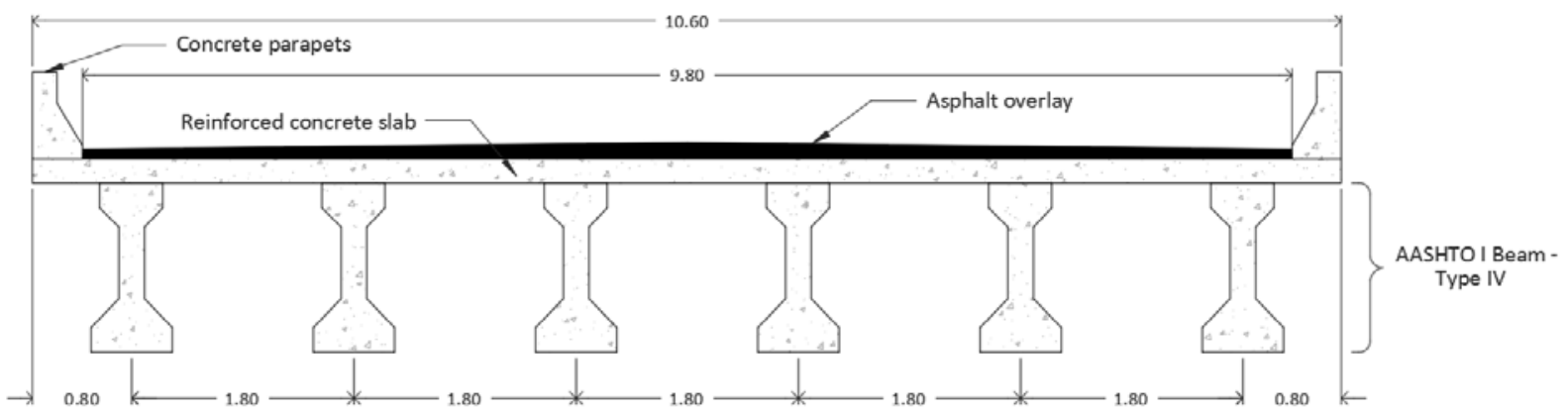

Figure 2: Transverse cross-section of the superstructure

Two types of support conditions are considered in the models, namely: (a) girders supported on pinned bearings, and (b) girders supported on elastomeric bearings, whose size is $0.30 \times 0.30 \times 0.057 \mathrm{~m}$ (width $\times$ length $\times$ height). There is an expansion joint at both ends of the bridges and the abutment stiffness was not explicitly included in the models.

The compressive strength of the RC bridge members is $f^{\prime}{ }_{c}=25 \mathrm{MPa}$, and $f^{\prime}{ }_{c}=35 \mathrm{MPa}$ for the PC bridge members. The elastic modulus of concrete, $E_{c}$, depends on the concrete compressive strength $\left[E_{c}=4400 \mathrm{~V}\left(f^{\prime} c\right)\right]$, then $E_{c}$ of the RC bridge members is $E_{C R}=22^{\prime} 000 \mathrm{MPa}$, and $E_{C P}=$ $26^{\prime} 030 \mathrm{MPa}$ for the PC bridge members. The modular ratio, $m$, between $\mathrm{RC}$ and $\mathrm{PC}$ is given by $m=E_{c R} / E_{c P}$. Thus, the modular ratio for the RC slab and PC girders is $m=0.8452$. The yield strength of the reinforcing bars is $F_{y}=411.90 \mathrm{MPa}$.

The dynamic behavior of the RC simple-span bridges is studied with 3-D FE models and grillage models, both considering flexible deck. The analytical models for the bridges were developed with SAP2000 software (CSI 2015).

\subsection{Finite Element (FE) Models}

The simplest 3-D FE model represents the superstructure components using shell and beam elements. Special consideration is required on the interface of the slab and the beams to account for the beam's center of gravity position (Mabsout et al. 1997, Meng and Lui 2000, Zahrai and Bruneau 1998).

RC slabs in the 3-D FE models were modeled with quadrilateral shell elements, using a mesh of $1.67 \times 1.80 \mathrm{~m}$, whereas girders and diaphragms were modeled with frame elements. Small discrete segments divide frame elements with mass assigned equally at each node, and same amount of mass acting in the longitudinal and transverse directions. The composite action between slab and girders was achieved by assigning joint offsets to the shell elements (Figure 3). The elastomeric bearings were modeled with link-type elements. 

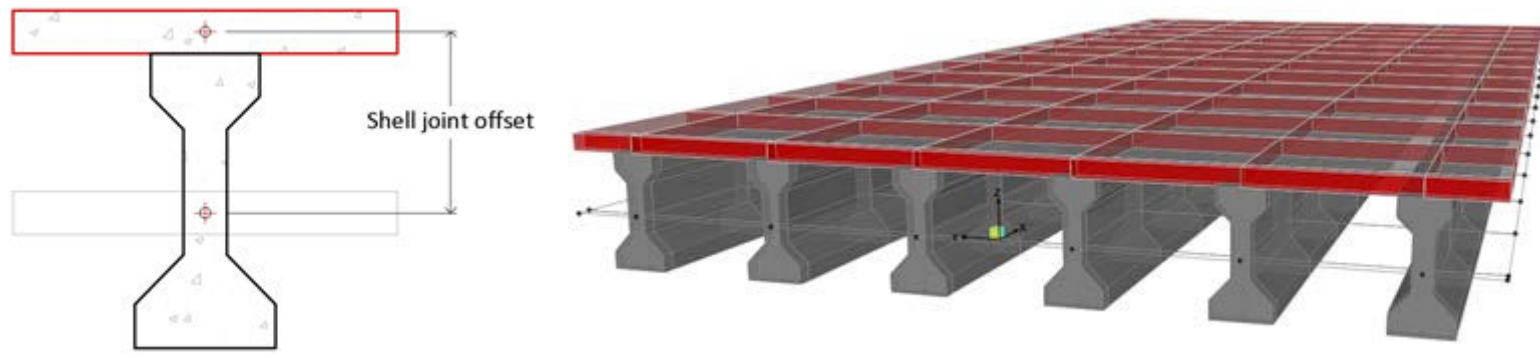

Figure 3: Slab and girders composite action

\subsection{Grillage Models}

There are two important steps in grillage modeling approach: (i) to simulate the bridge structure into equivalent grillage mesh, and (ii) to assign appropriate elastic properties to each member of the grillage. For the first step and given the great variety of bridge typologies, there are not specific guidelines to choose a grillage mesh for a skewed bridge. A suitable grillage mesh for skewed bridges depends on the skew angle, the span length, and the deck width. In this study, we considered the general recommendations suggested in the literature (Hambly 1991, OBrien, Keogh, and O'Connor 2015, Surana and Agrawal 1998).

The second step of the grillage modeling approach is to assign appropriate properties to the grillage members to obtain similitude between the grillage model and the corresponding bridge slab. To achieve similitude of bending moments between the slab and the corresponding grillage, it is necessary to adopt the same elastic modulus, $E_{c}$, and second moment of area, $I$, per unit breadth in the grillage as that of the slab. To achieve similitude of twisting moments in the slab and torques in the grillage members, it is necessary to adopt the same shear modulus, $G_{c}$, and torsion constant, $T$, in the grillage member as in the slab.

\subsubsection{Longitudinal Grillage Members (LGMs) - Geometric Definition and Properties}

The longitudinal grillage members (LGMs) are coincident with the centerlines of the girders. Figure 4 shows the cross-section of the slab-girder deck and the associated portion of slab represented by appropriate LGM. The self-weight of the slab is only applied to the LGMs representing the girders. Additional LGMs of nominal stiffness are placed along the outer edges to define the overall width of the superstructure (Hambly 1991).

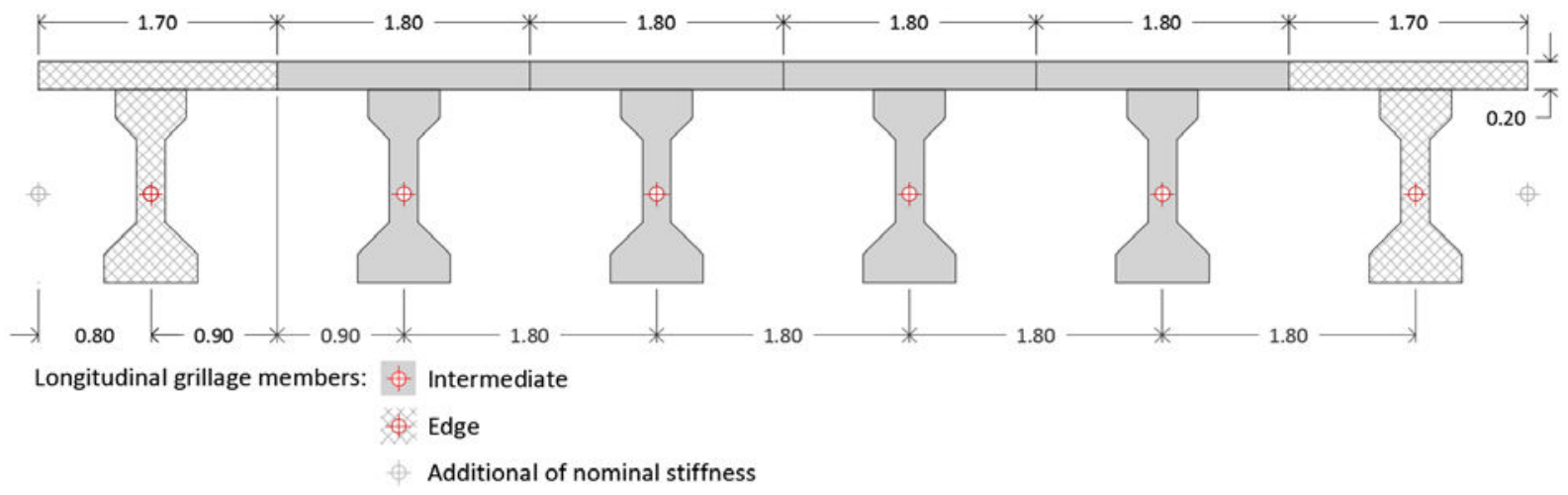

Figure 4: Slab+girder cross-sections represented by LGMs

For simplicity, $E_{c}$ as well as $G_{c}$ of prestressed concrete was assigned to all the LGMs. Since the RC slab has lower elastic modulus than the PC girders, the elastic modulus of the associated portion of slab of each LGM was reduced by factoring it by the modular ratio $m=0.8452$. The torsional constant of the LGMs was calculated as the sum of the torsional constants of the girder and the associated portion of slab. The former was calculated by the section designer function of SAP2000, while that of the slab was calculated with equation (1). 


$$
T=\left(b d^{3}\right) / 6
$$

where $b$ is the slab width represented by the LGM, while $d$ is the slab thickness.

\subsubsection{Transverse Grillage Members (TGMs) - Geometric Definition and Properties}

According to OBrien, Keogh, and O'Connor (2015), the recommended spacing of transverse grillage members (TGMs) should be similar to that of LGMs. Since the spacing between LGMs is $1.80 \mathrm{~m}$, the effective span length was divided into 12 parts. Thus, the resulting spacing of TGMs is $1.67 \mathrm{~m}$. The $I$ and $T$ properties of the TGMs representing the slab are calculated with equation (2) and equation (1), respectively. In this case, $b$ is the slab width represented by the TGM.

$$
I=\left(b d^{3}\right) / 12
$$

The TGMs should generally be oriented perpendicular to the LGMs unless the transverse reinforcement is in the skew direction. To assess the grillage model accuracy of the TGMs, bridge models with two different TGM orientations were developed, as shown in Figure 5: (a) TGMs in the skew direction, and (b) TGMs perpendicular to the LGMs.

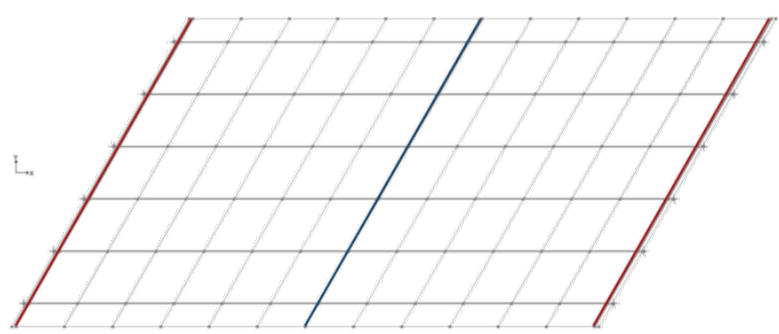

(a)

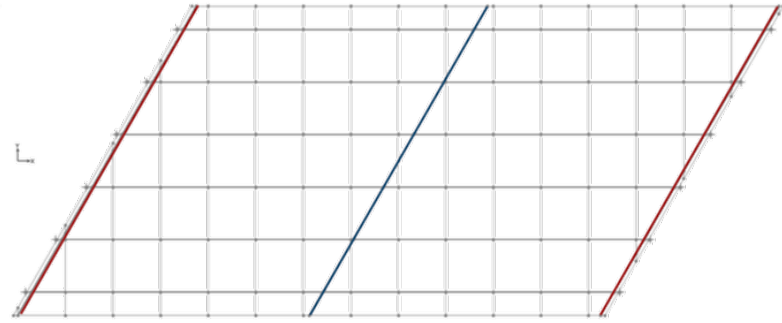

(b)

- end diaphragms - intermediate diaphragms

Figure 5: TGM orientation: (a) TGMs in the skew direction, and (b) TGMs perpendicular to the LGMs

$\mathrm{RC}$ end diaphragms and an intermediate diaphragm represented by TGMs are considered in the bridge models. As the diaphragms are aligned along the skew angle, their properties were only modified when the TGMs, representing the slab, were oriented in the skew direction (Figure 5a). In this case, the second moment of area of each TGMs was calculated about the centroid of the section it represents. In addition, the torsional constant is calculated as the sum of the torsional constants of the diaphragm and the associated portion of slab. $E_{c}$ and $G_{c}$ of reinforced concrete were assigned to all the TGMs.

\section{Modal Analysis}

\subsection{Terminology}

To compare the natural vibration frequencies, the mode shapes, and mass participation factors of the first 12 modes, modal analyses were conducted. The following nomenclature, uvwwxxy-zz, identifies the bridge models:

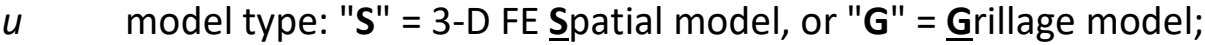

$v \quad$ model name: "T" if the grillage model has TGMs perpendicular to the LGMs (or if the 3-D FE model has right-angled shell elements);

ww skew angle: "00", "15", "30", "45", or "60";

$x x \quad$ model name: "ID" if the bridge model has an Intermediate Diaphragm;

$y \quad$ type of supports: "a" = pinned bearings, or "b" = elastomeric bearings, and 
number of elements to divide the girder; in the study the girders were divided into 12 elements.

\subsection{Natural Vibration Frequencies - 3-D FE Bridge Models}

The effect of the skew angle on the natural vibration frequencies of the 3-D FE bridge models was studied. Figures 6 and 7 display the natural vibration frequencies associated with the first 12 modes for the 3-D FE models supported on elastomeric and pinned bearings, respectively.

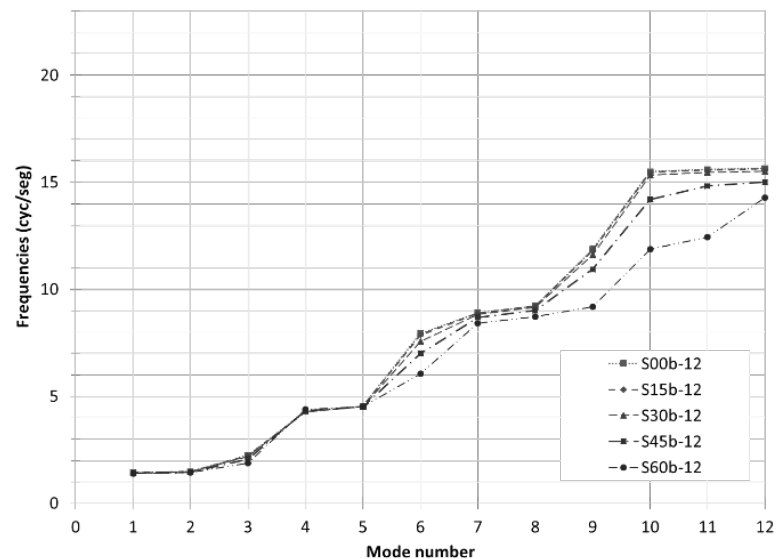

(a)

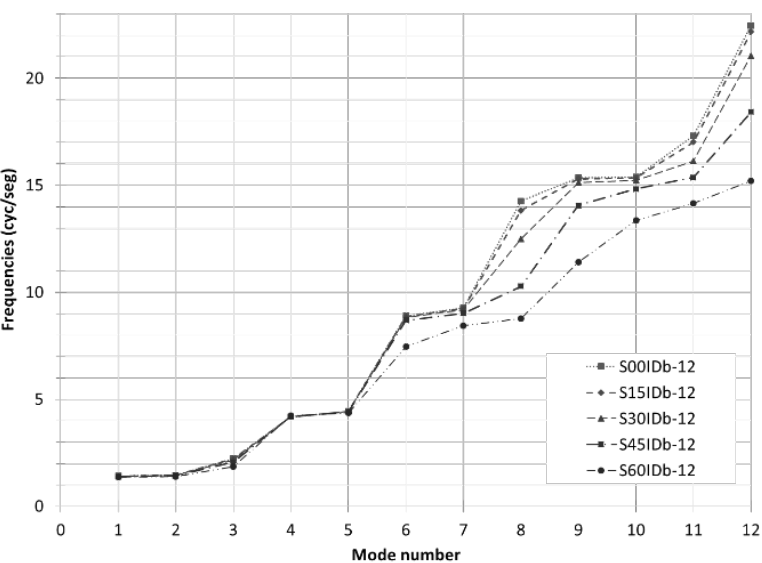

(b)

Figure 6: Natural vibration frequencies of the 3-D FE bridge models, elastomeric bearings: (a) without ID, and (b) with ID

The first five natural vibration frequencies of the bridge models supported on elastomeric bearings are not greatly affected by the skew angle (Figure 6). However, frequencies for higher modes tend to be smaller with the increase of the skew angle. This trend is even more evident in bridge models with intermediate diaphragms (Figure 6b). The first frequencies are nearly the same between bridge models with and without intermediate diaphragm. This result is a consequence of the rigid-body movement that dominates the first few vibrations modes, due to the presence of elastomeric bearings. In order to evaluate the ability of grillage models to capture other than rigid-body modes, bridge models supported on pinned bearing were developed and analyzed as well.

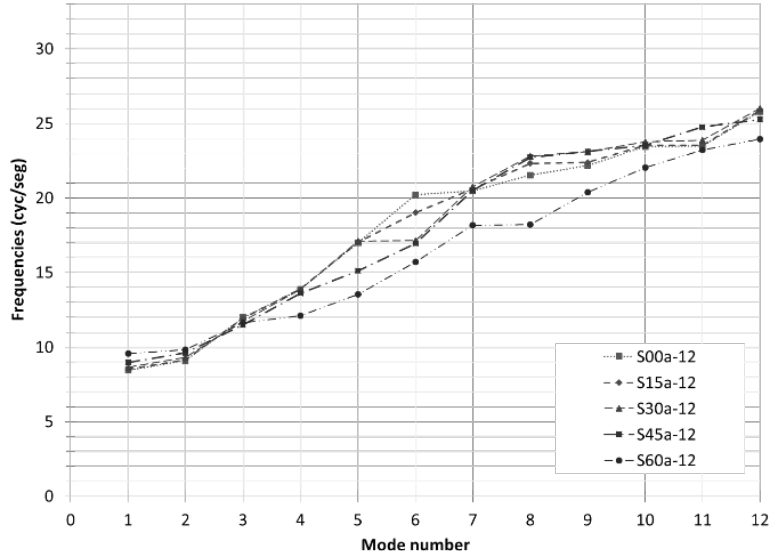

(a)

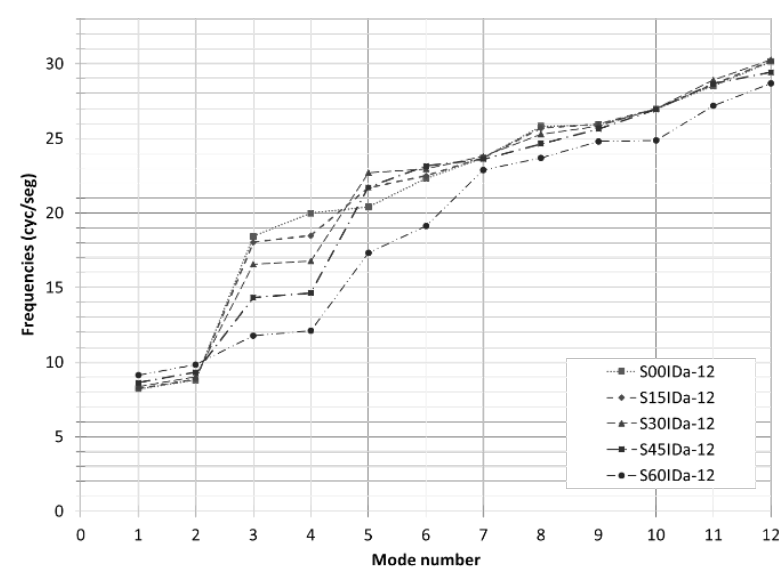

(b)

Figure 7: Natural vibration frequencies of the 3-D FE bridge models, pinned bearings: (a) without ID, and (b) with ID

Skew angle does not have any visible trend in bridge models supported on pinned bearings without intermediate diaphragms (Figure 7a). For each skew angle, the $1^{\text {st }}$ (torsional) and $2^{\text {nd }}$ (longitudinal flexural) modes and frequency values are nearly the same between bridge 
models, independently of the presence of intermediate diaphragms. Nonetheless, the $3^{\text {rd }}$ and $4^{\text {th }}$ modes of models with intermediate diaphragms are greatly affected by the skew angle (Figure $7 b$ ).

The $3^{\text {rd }}$ mode of $0^{\circ}$ and $15^{\circ}$ skewed bridge models is a transverse flexural mode, which is independent of the intermediate diaphragms. However, for $30^{\circ}$ and $45^{\circ}$ skewed bridge models, the $3^{\text {rd }}$ mode (transverse flexural) of models without ID corresponds to the $4^{\text {th }}$ mode of models with ID. The $3^{\text {rd }}$ mode of the latter models is a coupled flexural-torsional mode and its frequency is almost the same of the $4^{\text {th }}$ mode. The coupled flexural-torsional mode for the $15^{\circ}$ skewed bridge is the $4^{\text {th }}$ one. In all cases, the intermediate diaphragm increases the frequency values of the $3^{\text {rd }}$ and $4^{\text {th }}$ modes. This effect tends to be smaller with the increase of the skew angle.

The $60^{\circ}$ skewed bridge models (with and without ID) present the highest frequency values for the first two modes and the lowest one's for the remaining modes. The intermediate diaphragm does not affect the behavior of such bridge models for the first few modes, presenting correspondence between mode shapes and frequencies of the first four modes.

\subsection{Comparison of Bridge Modeling Techniques}

To continue evaluating the grillage and 3-D FE models methodologies, natural vibration frequencies, mode shapes, and modal participating mass ratios were studied. To compare mode shapes of both models, the Modal Assurance Criterion (MAC) was used. The MAC is a mathematical tool used to compare two vectors, providing a measure of the least-squares deviation or scatter of the point from straight-line correlation. The MAC can be used to determine the degree of consistency between modes shapes (Pastor, Binda, and Harčarik 2012), and it is bounded between 0 and $1 ; 1$ indicating fully consistent mode shapes.

The MAC between two modes shape vectors $\left\{\varphi_{g}\right\}_{r}$ and $\left\{\varphi_{s}\right\}_{q}$ is defined as,

$$
\operatorname{MAC}\left(\left\{\varphi_{g}\right\}_{r},\left\{\varphi_{s}\right\}_{q}\right)=\frac{\left[\left\{\varphi_{g}\right\}_{r}^{T}\left\{\varphi_{s}\right\}_{q}\right]^{2}}{\left[\left\{\varphi_{g}\right\}_{r}^{T}\left\{\varphi_{g}\right\}_{r}\right]\left[\left\{\varphi_{s}\right\}_{q}^{T}\left\{\varphi_{s}\right\}_{q}\right]}
$$

where $\left\{\varphi_{g}\right\}_{r}$ and $\left\{\varphi_{s}\right\}_{q}$ are the modal vector of the grillage model for mode $r$ and the modal vector of the 3-D FE model for mode $q$, respectively, while $\left\{\varphi_{g}\right\}_{r}^{T}$ and $\left\{\varphi_{s}\right\}_{q}^{T}$ are the transpose of the aforementioned modal vectors.

Figure 8 shows the comparison of the natural vibration frequencies, mode shapes, and modal participating mass ratios between grillage models and 3-D FE models. The information included in these figures is:

(i) MAC matrix (in 2-D plot) for the first 12 modes;

(ii) Cumulative sum of the square root of the squares' sum of modal participating mass ratios for each of the degrees of freedom (translational - solid line; rotational --dashed line). Grillage model and 3-D FE model plotted at the top and at the left side of the figure, respectively. This information illustrates how many modes shall be deemed to capture a certain level of accuracy for dynamic analysis, and

(iii) The bottom and the right side of the figure displays the computed natural vibration frequencies for the grillage model and 3-D FE model, respectively.

Figure 8 shows the results of the $45^{\circ}$ skewed bridge models with intermediate diaphragm supported on pinned bearings. Some modes switch, particularly the $3^{\text {rd }}$ and $4^{\text {th }}$ modes. In this case, the $3^{\text {rd }}$ mode of 3-D FE model corresponds to the $4^{\text {th }}$ mode of grillage model, and vice 
versa. The closely frequency values of the $3^{\text {rd }}$ and $4^{\text {th }}$ modes of each skewed bridge model with intermediate diaphragms, observed from the slope of the lines plotted in Figure $7 \mathrm{~b}$, justifies this behavior.

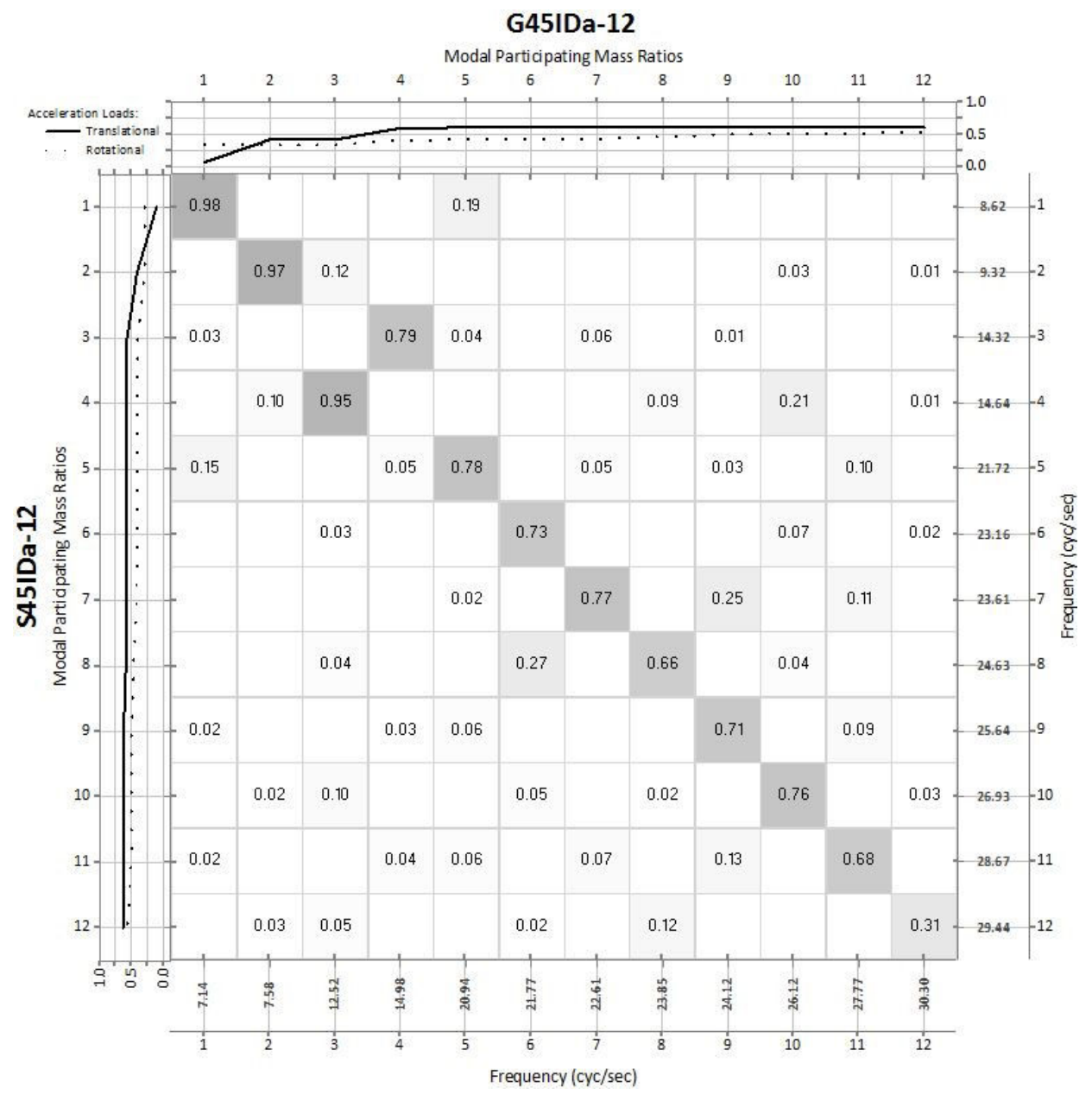

Figure 8: Comparison of bridge modeling techniques (example: G45IDa-12 \& S45IDa-12)

Figure 9 shows the undeformed shape and the deformed shapes of G45IDa-12 \& S45IDa-12 models, for the first eight modes. Since the MAC matrix (Figure 8 ) showed that $3^{\text {rd }}$ and $4^{\text {th }}$ vibration modes between bridge models are switched, Figure 9 draws the $3^{\text {rd }}$ mode shape of 3-D FE model (" $3^{\text {rd }}$ mode shape") and the $4^{\text {th }}$ one of grillage model in the same plot (and vice versa for " $4^{\text {th }}$ mode shape"). This mode shape comparison clearly shows that the grillage models are able to accurately capture higher vibration modes.

For a better understanding of the results, Figure 10 and Figure 11 show the main diagonal elements of MAC matrixes, as well as the elements immediately above and below the main diagonal, for bridge models supported on pinned and elastomeric bearings, respectively. The vertical axis displays the frequency ratio, $f_{G} / f_{S}$, between grillage and 3-D FE bridge models for the first 12 modes. In both figures, the left side presents the results of bridge models without intermediate diaphragms and right side the results of models with intermediate diaphragms. For each skew angle (with the exception of $0^{\circ}$ ), Figure 10 shows models with TGMs oriented in the skew direction (up) and models with TGMs perpendicular to the LGMs (bottom). The results show that orienting the TGMs perpendicular to the LGMs does not greatly improve the ability of the grillage models to capture the vibration modes. This trend was also noted in the results of bridge models supported on elastomeric bearings. 


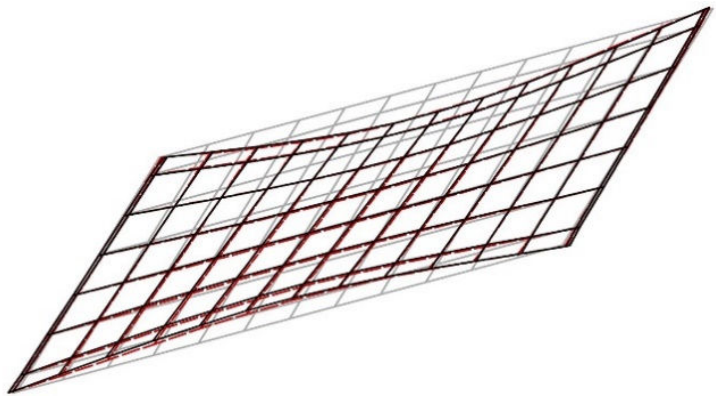

$1^{\text {st }}$ mode shape

$f_{S 1}=8.62 \mathrm{cyc} / \mathrm{seg}, f_{G 1}=7.14 \mathrm{cyc} / \mathrm{seg}$

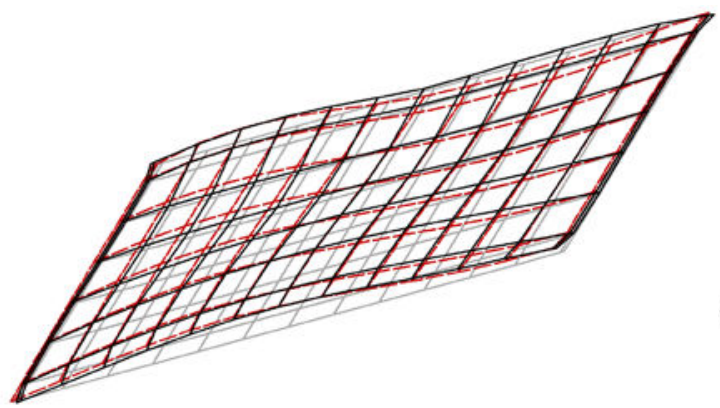

$3^{\text {rd }}$ mode shape*

$f_{S 3}=14.32 \mathrm{cyc} / \mathrm{seg}, f_{G 4}=14.98 \mathrm{cyc} / \mathrm{seg}$

*In the above figures, "3rd mode shape vice versa for " $4^{\text {th }}$ mode shape").

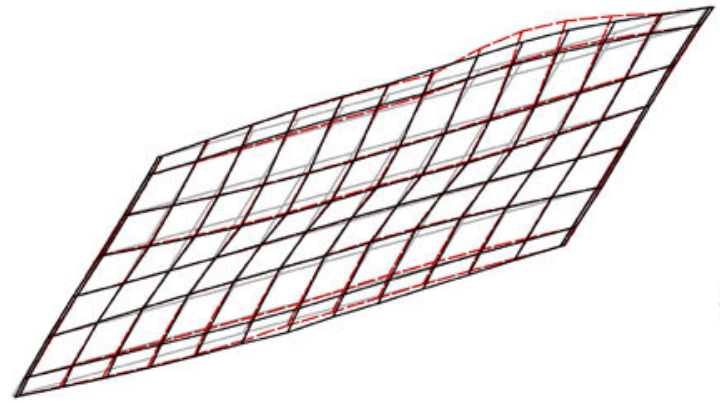

$5^{\text {th }}$ mode shape

$f_{S 5}=21.72 \mathrm{cyc} / \mathrm{seg}, f_{G 5}=20.94 \mathrm{cyc} / \mathrm{seg}$

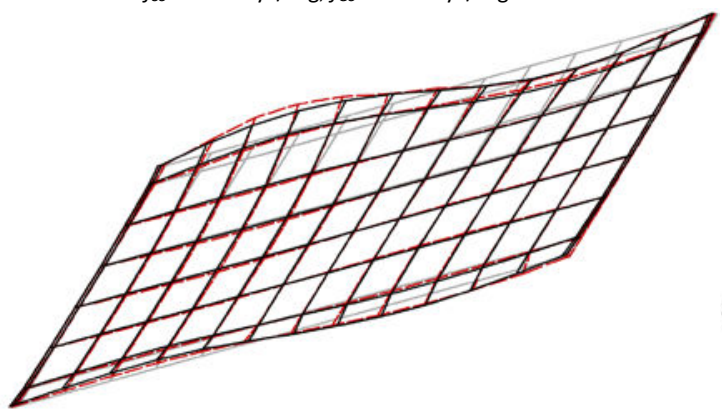

$7^{\text {th }}$ mode shape

$f_{S 7}=23.61 \mathrm{cyc} / \mathrm{seg}, f_{G 7}=22.61 \mathrm{cyc} / \mathrm{seg}$

undeformed shape; deformed shape:

Figure 9: S45IDa-12 \& G45IDa-12 mode shapes
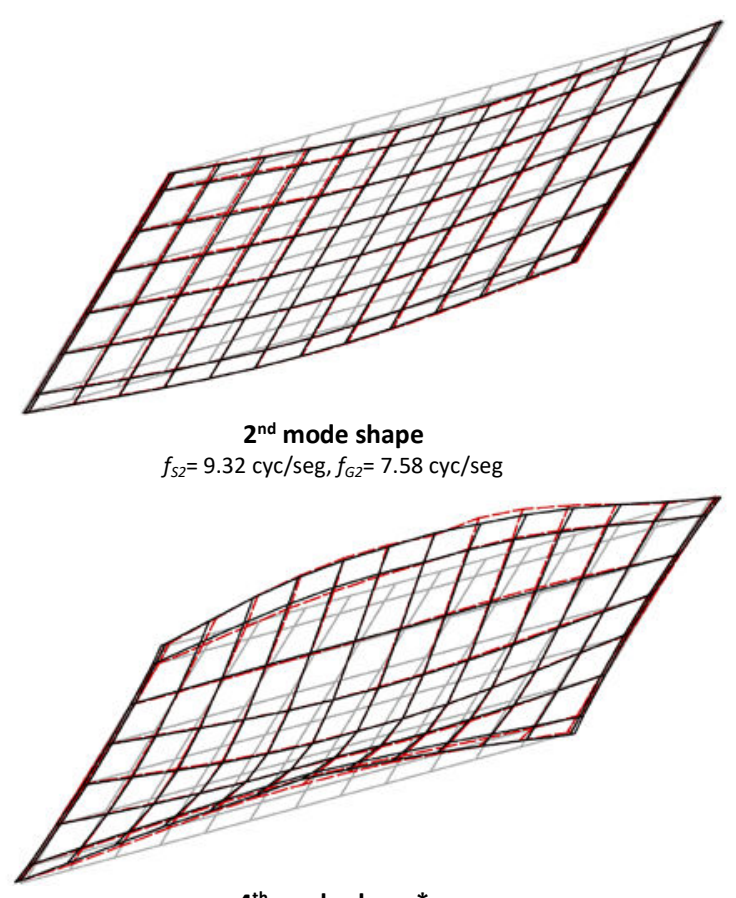

$f_{S 4}=14.64 \mathrm{cyc} / \mathrm{seg}, f_{G 3}=12.52 \mathrm{cyc} / \mathrm{seg}$

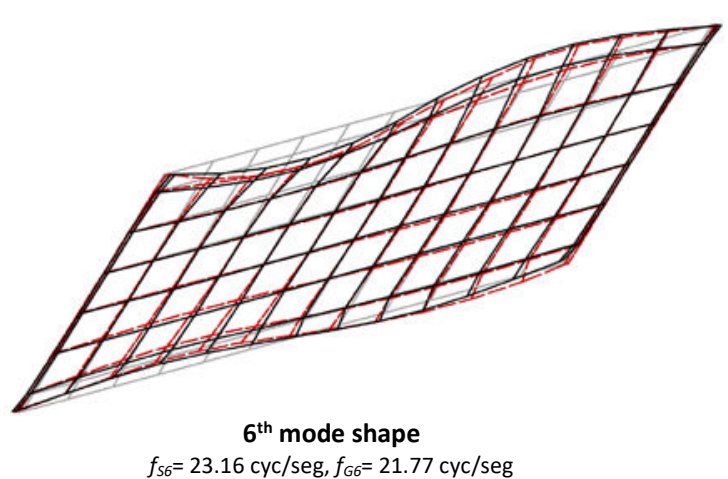

$f_{S 6}=23.16 \mathrm{cyc} / \mathrm{seg}, f_{G 6}=21.77 \mathrm{cyc} / \mathrm{seg}$

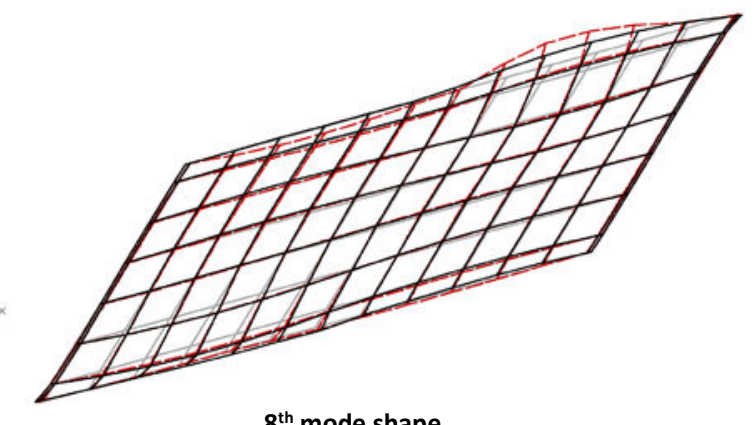

$f_{S 8}=24.63 \mathrm{cyc} / \mathrm{seg}, f_{G 8}=23.85 \mathrm{cyc} / \mathrm{seg}$ 

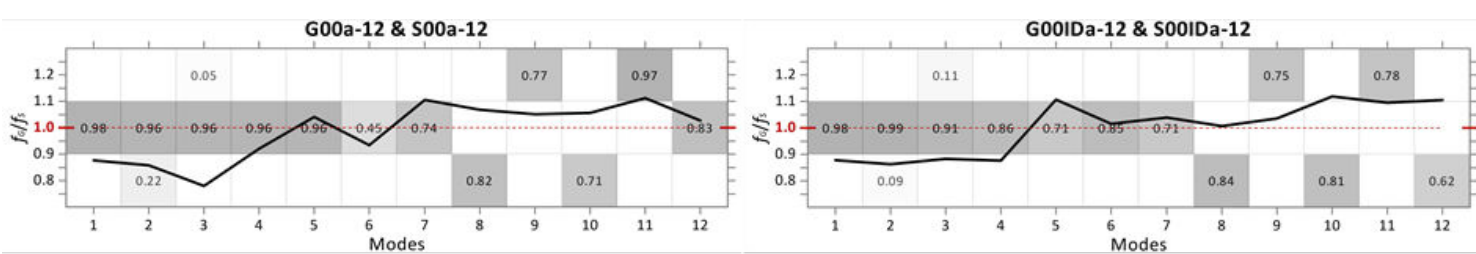

(a) $0^{\circ}$
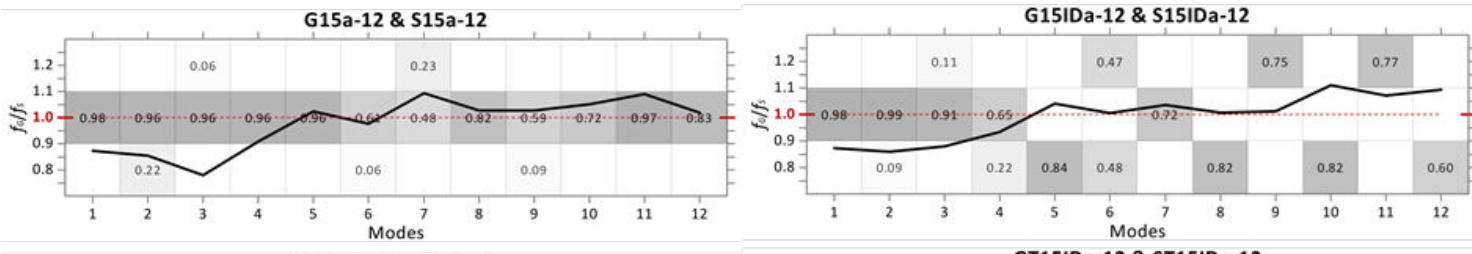

GT15a-12 \& ST15a-12
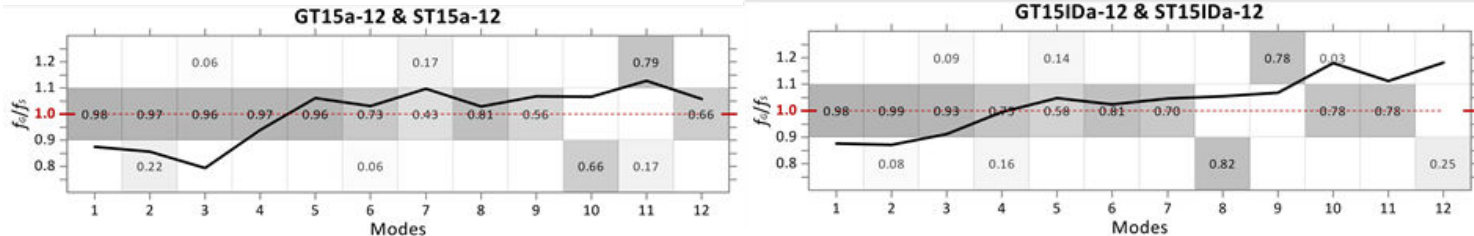

(b) $15^{\circ}$
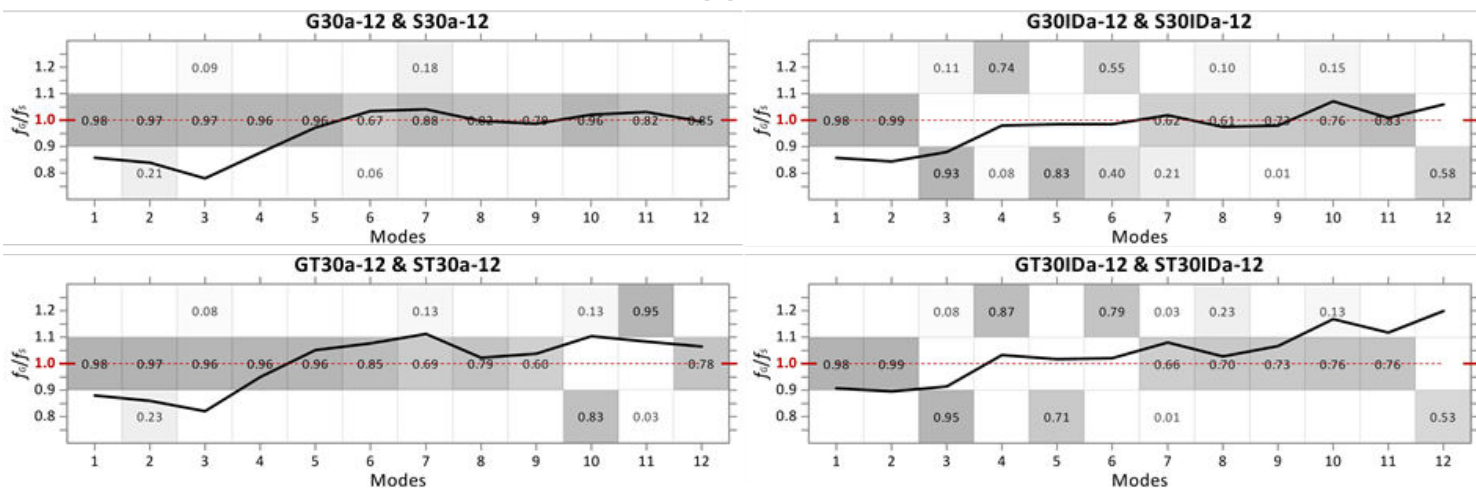

(c) $30^{\circ}$
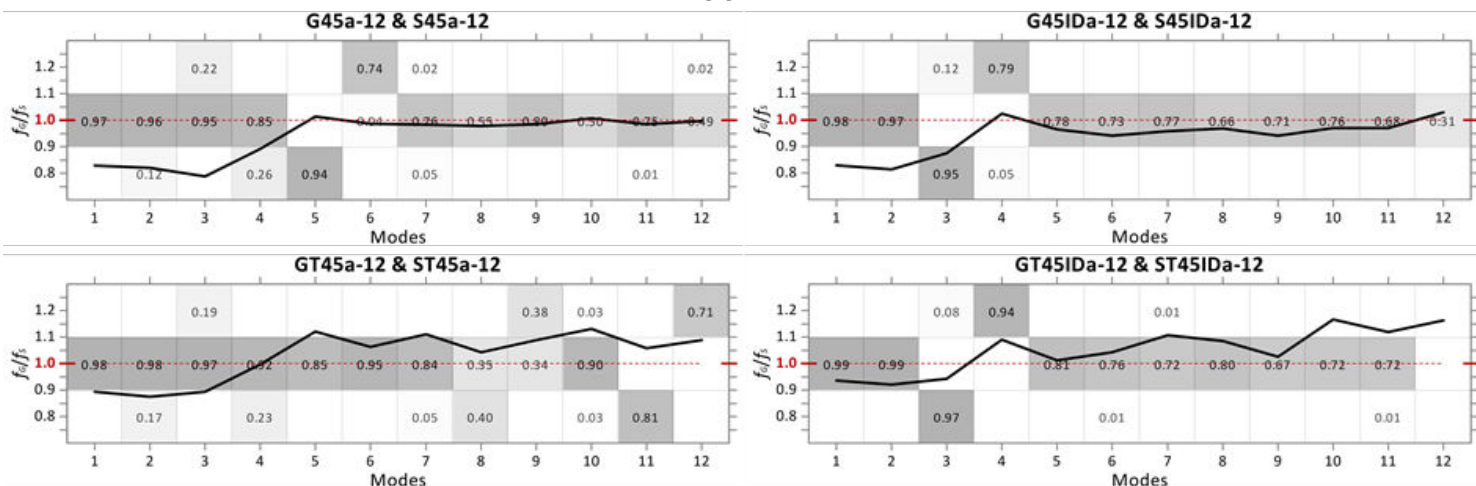

(d) $45^{\circ}$
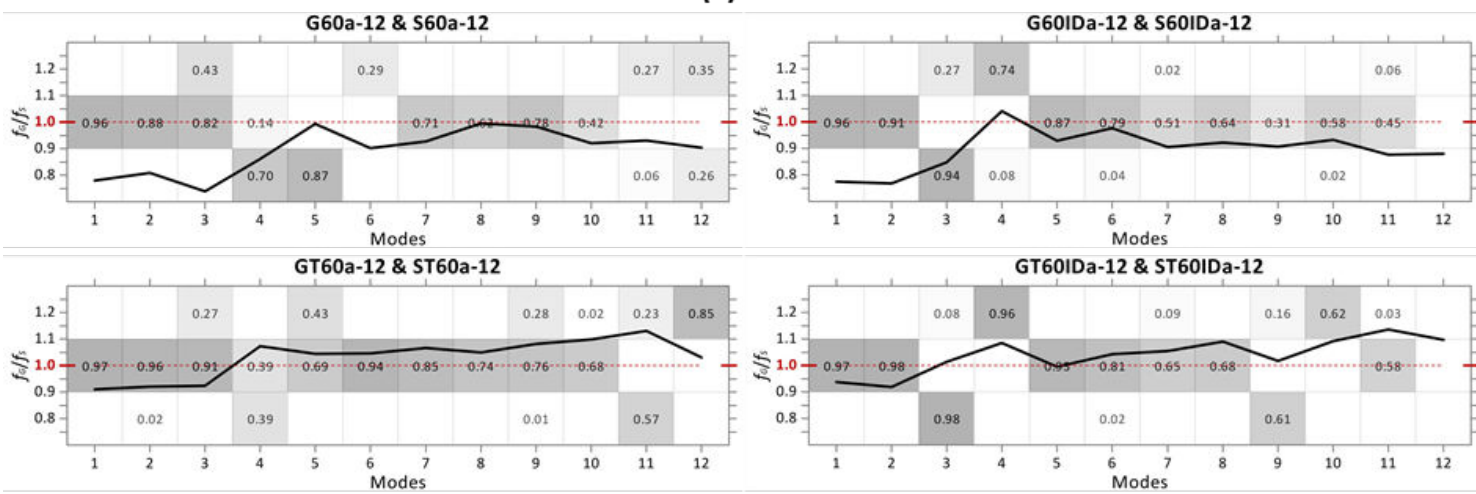

(e) $60^{\circ}$

Figure 10: Main diagonal of MAC matrixes, bridge models supported on pinned bearings 
Grillage models of bridges supported on elastomeric bearings with TGMs oriented in the skew direction, present MAC values up to 0.94 for the first eight modes (Figure 11), which indicates a noticeable agreement in almost all cases (with the exception of G60b-12 bridge model). The frequency ratio values, $f_{G} / f_{S}$, between grillage and 3-D FE bridge models for the first modes are close to 1 .
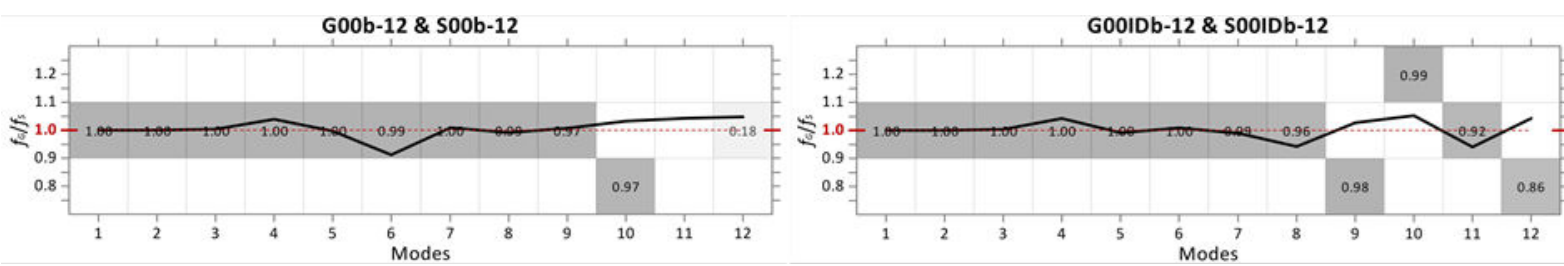

(a) $0^{\circ}$
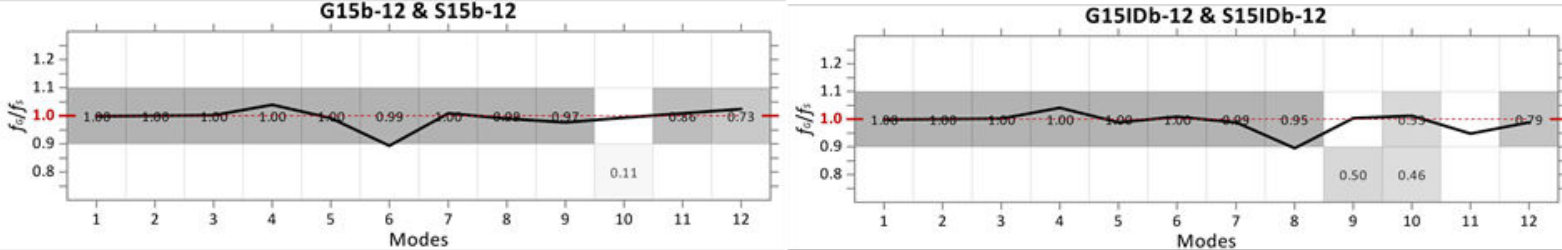

(b) $15^{\circ}$
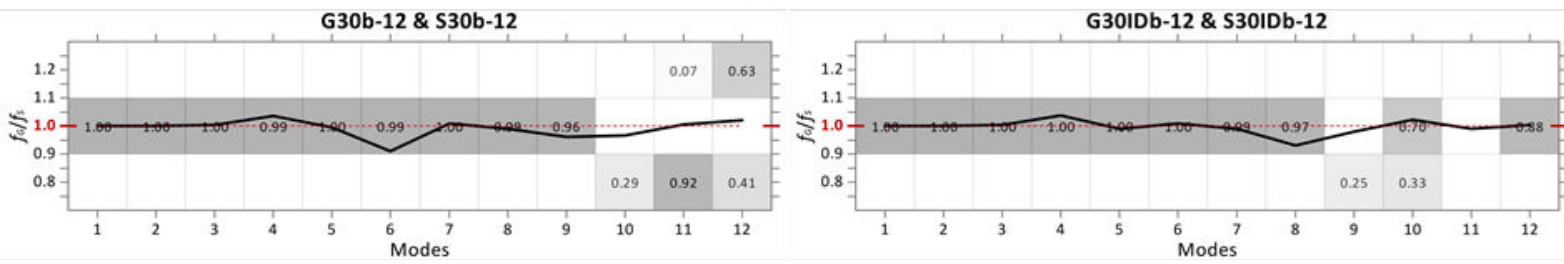

(c) $30^{\circ}$
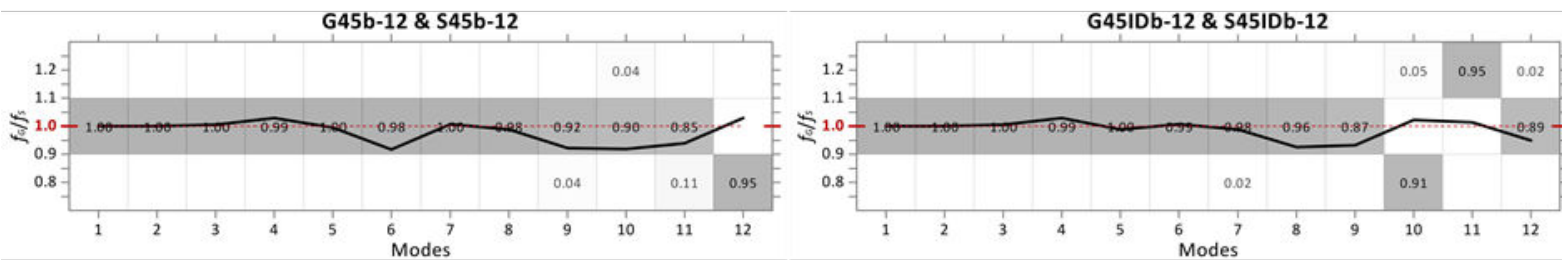

(d) $45^{\circ}$
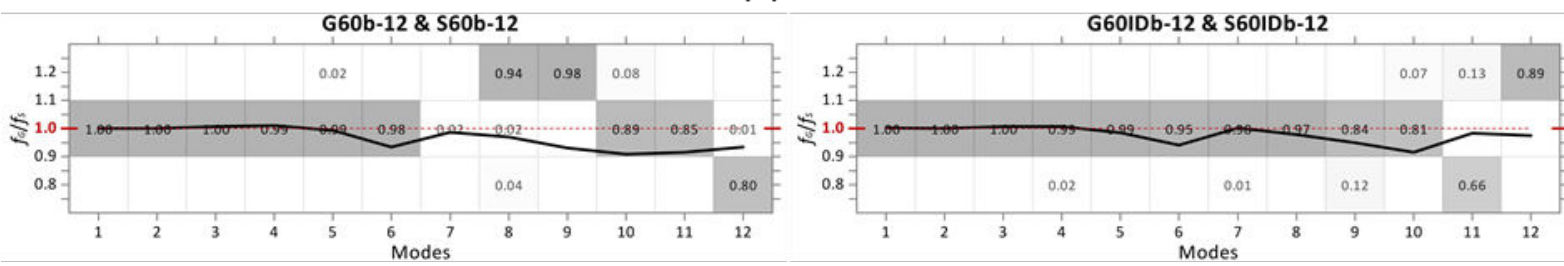

(e) $60^{\circ}$

Figure 11: Main diagonal of MAC matrixes, bridge models supported on elastomeric bearings

\section{Conclusions}

The applicability of a simplified modeling technique to simple-span slab-girder skewed bridges for dynamic analysis, based on grillage modeling strategies, was investigated. The response of bridge models with skew angle ranging from $0^{\circ}$ to $60^{\circ}$ was studied. The grillage approach was selected as a modeling technique due to its simplicity to use. 3-D FE models (shell and beam models) illustrate the ability of the simplified approach to capture vibration modes. Based on the results, the following conclusions are drawn:

- The first natural vibration frequencies of bridge models supported on elastomeric bearings is not greatly affected by the skew angle, contrary to the results of bridge models supported on pinned bearings. 
- The intermediate diaphragm, aligned along the skew angle, introduces an additional mode (coupled flexural-torsional mode), increasing the frequency values for the first few modes. However, this effect tends to be smaller with the increase of the skew angle.

- The orientation of TGMs perpendicular to the LGMs does not greatly improve the ability of the grillage models to capture the vibration modes.

- According to the comparative analysis, grillage models are able to accurately capture higher vibration modes

- Even though a bridge superstructure is usually strong enough to remain elastic under seismic loads, the reduction of degrees of freedom in the bridge models makes grillage modeling approach suitable for computationally intensive studies, as those involving a large number of nonlinear time-history analyses.

- For further validation of the modeling techniques, a comparison of the methods performance should be carried out, in terms of nonlinear analysis.

\section{References}

AASHTO. 2012. AASHTO LRFD Bridge Design Specifications, Customary U.S. Units. 6th ed. Washington D.C.: American Association of State Highway and Transportation Officials.

Abdel-Mohti, A., and G. Pekcan. 2013. "Assessment of seismic performance of skew reinforced concrete box girder bridges." International Journal of Advanced Structural Engineering (IJASE) 5 (1):1-18. DOI: 10.1186/2008-6695-5-1.

Aviram, A., K. R. Mackie, and B. Stojadinovic. 2008. Guidelines for nonlinear analysis of bridge structures in California. Berkeley, California: Pacific Earthquake Engineering Research Center, University of California.

Bjornsoon, S., J. Stanton, and M. Eberhard. 1998. "Seismic response of skew bridges." Proceedings of the 6th U.S. National Conference on Earthquake Engineering, Seattle, Washington.

SAP2000 17.3.0. Computers and Structures, Inc., Berkeley, California.

Ghobarah, A. A., and W. K. Tso. 1974. "Seismic analysis of skewed highway bridges with intermediate supports." Earthquake Engineering \& Structural Dynamics 2 (3):235-248. DOI: 10.1002/eqe.4290020304.

Hambly, E. C. 1991. Bridge deck behaviour. New York: Taylor \& Francis.

Haque, M. N., and M. A. R. Bhuiyan. 2012. "Seismic response analysis of simple span concrete deck girder skewed bridge: effect of skew angles." Journal of Civil Engineering (IEB) 40 (2):227-237.

Jennings, P. C., G. W. Housner, D. E. Hudson, M. D. Trifunac, G. A. Frazier, J. H. Wood, R. F. Scott, W. D. Iwan, and A. G. Brady. 1971. Engineering features of the San Fernando earthquake of February 9, 1971. Pasadena, California: California Institute of Technology.

Kaviani, P., F. Zareian, and E. Taciroglu. 2014. Performance-based seismic assessment of skewed bridges. Berkeley, California: Pacific Earthquake Engineering Research Center, University of California.

Mabsout, M. E., K. M. Tarhini, G. R. Frederick, and C. Tayar. 1997. "Finite-element analysis of steel girder highway bridges." ASCE Journal of Bridge Engineering 2 (3):83-87. DOI: 10.1061/(ASCE)1084-0702(1997)2:3(83).

Maleki, S. 2001. "Free vibration of skewed bridges." Journal of Vibration and Control 7 (7):935952. DOI: 10.1177/107754630100700701. 
Maleki, S., and H. Hojat Jalali. 2012. "Seismic behavior of concrete end-diaphragms in straight slab girder bridges." Proceedings of the 1st ASEA-SEC International Structural Engineering \& Construction Conference, Perth, Australia.

Maragakis, E. A., and P. C. Jennings. 1987. "Analytical models for the rigid body motions of skew bridges." Earthquake Engineering \& Structural Dynamics 15 (8):923-944. DOI: 10.1002/eqe.4290150802.

Memory, T. J., D. P. Thambiratnam, and G. H. Brameld. 1995. "Free vibration analysis of bridges." Engineering Structures 17 (10):705-713. DOI: 10.1016/0141-0296(95)00037-8.

Meng, J. Y., and E. M. Lui. 2000. "Seismic analysis and assessment of a skew highway bridge." Engineering Structures 22 (11):1433-1452. DOI: 10.1016/s0141-0296(99)00097-8.

Meng, J. Y., and E. M. Lui. 2002. "Refined stick model for dynamic analysis of skew highway bridges." ASCE Journal of Bridge Engineering 7 (3):184-194. DOI: 10.1061/(ASCE)10840702(2002)7:3(184).

Meng, J. Y., E. M. Lui, and Y. Liu. 2001. "Dynamic response of skew highway bridges." Journal of Earthquake Engineering 5 (2):205-223. DOI: 10.1080/13632460109350392.

OBrien, E. J., D. Keogh, and A. O'Connor. 2015. Bridge deck analysis. 2nd ed. Boca Raton, Florida: CRC Press.

Pastor, M., M. Binda, and T. Harčarik. 2012. "Modal assurance criterion." Modelling of Mechanical and Mechatronics Systems 48:543-548. DOI: 10.1016/j.proeng.2012.09.551.

Saiidi, M., and D. Orie. 1992. "Earthquake design forces in regular highway bridges." Computers \& Structures 44 (5):1047-1054. DOI: 10.1016/0045-7949(92)90327-v.

Surana, C. S., and R. Agrawal. 1998. Grillage analogy in bridge deck analysis. New Delhi: Narosa Publishing House.

Wakefield, R. R., A. S. Nazmy, and D. P. Billington. 1991. "Analysis of seismic failure in skew RC bridge." ASCE Journal of Structural Engineering 117 (3):972-986. DOI: 10.1061/(ASCE)07339445(1991)117:3(972).

Zahrai, S. M., and M. Bruneau. 1998. "Impact of diaphragms on seismic response of straight slab-on-girder steel bridges." ASCE Journal of Structural Engineering 124 (8):938-947. DOI: 10.1061/(ASCE)0733-9445(1998)124:8(938). 